\title{
Population based absolute and relative survival to 1 year of people with diabetes following a myocardial infarction: A cohort study using hospital admissions data
}

Sinead Brophy ${ }^{1 *}$, Roxanne Cooksey ${ }^{1}$, Michael B Gravenor ${ }^{1}$, Clive Weston ${ }^{1}$, Steven M Macey ${ }^{1}$, Gareth John², Rhys Williams ${ }^{1}$, Ronan A Lyons ${ }^{1}$

\begin{abstract}
Background: People with diabetes who experience an acute myocardial infarction (AMI) have a higher risk of death and recurrence of AMI. This study was commissioned by the Department for Transport to develop survival tables for people with diabetes following an AMI in order to inform vehicle licensing.

Methods: A cohort study using data obtained from national hospital admission datasets for England and Wales was carried out selecting all patients attending hospital with an MI for 2003-2006 (inclusion criteria: aged 30+ years, hospital admission for MI (defined using ICD 10 code I21-I22). STATA was used to create survival tables and factors associated with survival were examined using Cox regression.

Results: Of 157,142 people with an MI in England and Wales between 2003-2006, the relative risk of death or recurrence of $\mathrm{Ml}$ for those with diabetes $(\mathrm{n}=30,407)$ in the first 90 days was $1.3(95 \% \mathrm{Cl}$ : 1.26-1.33) crude rates and 1.16 (95\% Cl: 1.1-1.2) when controlling for age, gender, heart failure and surgery for MI) compared with those without diabetes ( $n=129,960)$. At 91-365 days post AMl the risk was 1.7 (95\% Cl 1.6-1.8) crude and 1.50 (95\%Cl: 1.4-1.6) adjusted. The relative risk of death or re-infarction was higher at younger ages for those with diabetes and directly after the AMI (Relative risk; RR: 62.1 for those with diabetes and 28.2 for those without diabetes aged 40-49 [compared with population risk]).

Conclusions: This is the first study to provide population based tables of age stratified risk of re-infarction or death for people with diabetes compared with those without diabetes. These tables can be used for giving advice to patients, developing a baseline to compare intervention studies or developing license or health insurance guidelines.
\end{abstract}

\section{Background}

Patients with diabetes who have an acute myocardial infarction (AMI) are at higher risk of death, both in the acute phase [1] and during follow-up [2-4]. In fact, cardiovascular disease is reported to account for almost $80 \%$ of all 'diabetic' deaths[5]. This may be because patients with diabetes often have a cluster of risk factors including hypertension, hypercholesterolemia, obesity, hyperglycemia, high risk lifestyle factors (such as smoking), albuminuria, and family history of disease [6] and

\footnotetext{
* Correspondence: s.brophy@swansea.ac.uk

'School of Medicine, Swansea University, SA2 8PP, UK
}

have a more complications in hospital following an MI [7]. For example, heart failure is twice as common in patients with type 2 diabetes [8] compared with those without type 2 diabetes. Thus, the short term mortality rate of a patient with diabetes is reported to be twice that in those without diabetes $[9,10]$ and patients with diabetes have reduced long term survival $[2,11]$. The relative risk of a primary $\mathrm{MI}$ is more common among women with type 2 diabetes than among men [12] However, there are currently few population-based estimates of the probability of survival following an AMI for 
people with diabetes compared with those without diabetes $[2,13]$ and none look at time to re-infarction.

This study was developed from a project commissioned by the UK Department for Transport [14] to develop absolute and relative risk survival tables to show time to death or recurrence of an AMI for diabetic and non-diabetic patients hospitalised for AMI. It presents absolute risk reference tables for people who experience an AMI stratified by age, sex and diabetes and separately absolute risk reference tables for controls who have not experienced a primary AMI.

\section{Methods}

\section{Design}

We conducted a cohort study of risk of death or recurrence of MI in people hospitalised for MI using all hospital admissions in England and Wales for the years 2003-2006.

\section{Datasets}

Data were obtained from two hospital admission datasets; PEDW - Patient Episode Database for Wales and HES - Hospital Episode Statistics for England. These datasets are publicly available on request to the data custodians. MI was defined using ICD code I21-I22 and diabetes using ICD 10 codes E10-E14. HES and PEDW records are held at a 'finished consultant episode' (FCE) level, which represent periods of care under a particular consultant while in hospital. One admission might therefore, result in more than one FCE. These FCE's were internally linked to develop 'hospital spells' for an individual and 'super-spells' that link hospital spells for patients transferred between hospitals during their index admission. Super-spells are records which give the entire patient journey through the hospital system. Data contained on the hospital admission systems includes demographics, diagnosis, surgery, admission and discharge information but it does not include prescriptions, symptoms or laboratory or other tests.

\section{Study population}

Patients admitted to hospital who were aged less than 30 years were excluded from the study. Diabetes was defined as ICD codes E10-E14 (Insulin dependent, noninsulin dependent, malnutrition-related diabetes mellitus, other specified diabetes, and other non-specified diabetes). Surgery for the current MI was recorded (OPCS codes K40 to K50 and K75) which includes angioplasty, CABG and stent placement. All patients were taken from admission to hospital for an AMI between the dates 2003-2006.

\section{Linkage}

An anonymised version of the PEDW database was linked with the Welsh NHS Administrative Register (AR) which records date of death or date of moving out of Wales. Therefore, an accurate estimation of death, or loss to follow-up due to leaving Wales, can be calculated. The HES dataset was linked with individual records of mortality held by the Office for National Statistics (ONS) using unique National Health Service (NHS) numbers [14]. Recurrent AMIs can be identified from readmissions to hospital. Patients who suffer AMI and die before reaching hospital cannot be identified by hospital-based systems, but can be identified using mortality data from AR and ONS. While there may be an underestimate of the number of re-infarctions the combined endpoint of re-infarction/death will include MI's resulting in death (without hospital admission). In the HES system patients who have moved out of England cannot be identified. This could have the effect of making the incidence of re-infarction and death slightly lower, since patients moving outside the UK who have an AMI or die cannot be identified. However, the number of people who moved out of England are relatively small and therefore unlikely to change the validity of the conclusions. In addition, patients who have a silent AMI, that is have a re-infarction but are not admitted and do not die, will be missed from this study.

\section{Control group}

The entire Welsh population was selected using people on the Welsh AR and those who were not recorded as having had an MI before the $1^{\text {st }}$ of January 2003 were extracted. The rate of AMI and death in this control group was determined using the same methods as those for the AMI patients. The control group provided population-based incidence rates of first AMI or mortality in those without an index AMI since 1996.

\section{Quality of the datasets}

Data from the Myocardial Ischaemia National Audit Project (MINAP) data [15] was obtained, with permission from the data guardians, for the period 1st April 2003-31 $1^{\text {st }}$ March 2006 in order to examine validity of data held in the hospital admissions dataset. MINAP is a dataset of patients hospitalised with AMI which is used to compare the management of myocardial infarction within hospitals against targets specified by the National Service Framework for Coronary Heart Disease (NSF). This dataset is not a population register of AMI as it is known that participation and recruitment differs by hospital (for example percentage of non-STEMI MI's varies between hospitals from $0.8 \%-73 \%$ )[14]. The original reason for setting up MINAP was the measurement of the process and outcomes of the care of patients with MIs amenable to reperfusion treatment. Non-STEMI is not managed by reperfusion therapy and so some hospitals have tended not to record data for this type of heart 
attack. Consequently, not all MIs are included in MINAP. However, we have used this database to examine if all MI's found in MINAP can be also found in PEDW. This dataset was linked with the Welsh hospital admission system (PEDW) using anonymised and encrypted NHS numbers to examine the extent of overlap, coding coherence and accuracy.

In addition, the out-patients clinical care system used by the diabetologists was linked with the hospital admissions system to examine the number of known diabetic patients (as identified from the diabetes clinical care system) who had any mention of diabetes in their admission to hospital.

\section{Statistical analysis}

STATA was used with the st command to examine survival (death alone or death and re-infarction) for patients stratified by age, sex and diabetes. Survival was analysed for the first 90 days, 91-180 days and 181-365 days. Factors associated with survival (diabetes, heart failure, age, gender and surgery [angioplasty/stenting, for the current MI]) were analysed using Cox regression. Interaction terms have not been included in the model as given the large numbers of patients all interaction terms are found to be significant and make interpretation of the model very difficult. Proportionality was examined by comparing graphs of the scaled Schoenfeld residuals.

\section{Results}

Data quality

In Wales, of 3,371 individuals recorded in MINAP attending Welsh hospitals, 3368 (99.91\%) were also found in PEDW, 2,987 (89\%) were found in PEDW with a diagnosis of AMI, 366 (10.9\%) were recorded in PEDW but with a non AMI diagnosis (e.g. diagnosed with chronic ischemic heart disease or angina pectoris), 3.9\% [15] were recorded as attending an English hospital with AMI and $3(0.1 \%)$ were recorded in MINAP but missing from PEDW altogether.

There was no significant difference between the number of people recorded in MINAP as having diabetes $(1620 / 8143$ - 19.9\%) compared with the number recorded on the hospital admission system, PEDW $(30,407 / 160,367-20 \%)$. Thus, there is no evidence of relative under ascertainment of diabetes when using the hospital admission systems. In addition, of 853 patients who had diabetes (as confirmed on the out-patients diabetologist clinical care system) and who had an inpatient hospital visit (either related or not related to the diabetes), 774 (90\%) had diabetes recorded during their hospital visit (for MI, cataract surgery, amputation).

Finally, in Wales, the number of people who moved outside of Wales in a 1 year period was $1.2 \%$. We would expect the numbers moving out of the UK to be of similar levels[16]. Thus, the error level in the patients from the England system is likely to be small.

\section{Demographics}

There were 30,407 (19\%) people with diabetes $(37.9 \%$ female, average age 70 (min-max: 30-120) and 129,960 (81\%) people (35\% female, average age 68.7 (min-max: 30-105) without diabetes. Among those with diabetes; $34.3 \%$ had heart failure and $15.3 \%$ had heart surgery for the MI. Among those without diabetes $20.6 \%$ had heart failure and $16.2 \%$ had heart surgery.

\section{Survival}

There were 157,142 people followed for 126,731 followup years within England and Wales. An additional 3225 were included in the dataset but had no follow-up time as they died on the date of admission (2\%), 8 patients were not followed as they were recorded as having moved out of Wales/UK and before the date of their admission for their MI. Within this timeframe there were 48,517 deaths or re-infarction events, giving an incidence of $38.3 \%$ (95\% CI: 37.9-38.6) per person year of follow-up. The risk of death was highest in the first 90 days [Table 1], and then declined. However, the risk of re-infarction remained high for the first 180 days (Figure 1). The combined rate of death or re-infarction was highest for those with diabetes [Table 2]. Patients with diabetes were at 1.16 (95\%CI: :1.1-1.2) times higher risk of death or re-infarction in the first 90 days, and at 1.5 (95\%CI: 1.4-1.6) times higher risk at 90-365 days post MI, when controlling for age, gender, heart failure and heart surgery [Table 3]. Therefore, the attributable risk of the diabetes increases 90 days post MI. However, this is because the absolute risk of death in the non diabetic group declines greatly with time (see Figure 1).

The population risk is given in Table 4 and the relative risk compared with population rates is given in Table 5. The risk attributable to having an AMI is highest in younger ages and directly after the MI (relative risk of death or re-infarction is 82.3 among women aged 40-49 with no diabetes at 0-90 days compared with 1.1 for women aged 90 at 181-365 days. The relative risk for those with diabetes is highest for younger patients. For example, there is a 2 fold higher risk of death or re-infarction for males with diabetes aged 50-59 at 0-90 days post MI (compared with those without diabetes, $38 / 18.6=2.0$ (95\%CI: 1.6-2.7) higher risk -Table 5). However, in males aged $90+$ there is no increased risk associated with having diabetes. $(12.5 / 11.9=1.05(95 \%$ CI: 0.82-1.9) at 0-90 days. Thus, the relative risk of mortality/re-infarction is more prominent in younger individuals with diabetes because the risk in controls is so much lower at a younger age. Age is a very strong 
Table 1 Mortality rates following an AMI per 1,000 people

\begin{tabular}{|c|c|c|c|c|c|c|c|}
\hline Gender and Co-morbidity & Age & $\begin{array}{l}\text { 0-90 days: } \\
\text { rate }(95 \% \mathrm{Cl})\end{array}$ & n & $\begin{array}{l}91-180 \text { days: } \\
\text { rate }(95 \% \mathrm{Cl})\end{array}$ & $\mathbf{n}$ & $\begin{array}{l}\text { 181-365 days: } \\
\text { rate }(95 \% \mathrm{Cl})\end{array}$ & $n$ \\
\hline \multicolumn{8}{|l|}{ Male } \\
\hline \multirow[t]{7}{*}{ No diabetes } & $30-39$ & $13(9-20)$ & 1,635 & $1.5(0.3-6.0)$ & 1414 & $2.1(0.8-5.6)$ & 1226 \\
\hline & $40-49$ & $17(14-20)$ & 7,894 & $3.5(2.3-5.3)$ & 6784 & $3.6(2.5-5.1)$ & 5722 \\
\hline & $50-59$ & $33(30-36)$ & 15,712 & $4.5(3.5-5.9)$ & 13276 & $4.3(3.5-5.4)$ & 11306 \\
\hline & $60-69$ & $77(73-82)$ & 18,701 & $15(12-17)$ & 15204 & $14(12-16)$ & 12761 \\
\hline & $70-79$ & $197(190-203)$ & 19,714 & $39(36-42)$ & 14224 & $37(34-40)$ & 11770 \\
\hline & $80-89$ & $395(383-407)$ & 14,732 & $85(79-92)$ & 8904 & $91(85-97)$ & 6989 \\
\hline & $90+$ & $705(665-749)$ & 2,548 & $170(140-190)$ & 1192 & $160(140-190)$ & 870 \\
\hline \multirow[t]{7}{*}{ Diabetes } & $30-39$ & $19(6-59)$ & 170 & $15(3.6-58)$ & 150 & $5.3(0.7-37.9)$ & 123 \\
\hline & $40-49$ & $36(25-51)$ & 987 & $5(2-14)$ & 811 & $11(5.9-19)$ & 701 \\
\hline & $50-59$ & $67(57-79)$ & 2626 & $15(11-22)$ & 2120 & 14(10-19) & 1808 \\
\hline & $60-69$ & $135(124-147)$ & 4496 & $25(20-32)$ & 3433 & $32(27-38)$ & 2875 \\
\hline & $70-79$ & $266(251-280)$ & 6133 & $62(54-70)$ & 4175 & $55(49-62)$ & 3374 \\
\hline & $80-89$ & $416(392-442.3)$ & 3528 & $130(110-140)$ & 2074 & $110(95-120)$ & 1529 \\
\hline & $90+$ & $704(604-817)$ & 402 & $250(180-340)$ & 190 & $160(110-230)$ & 124 \\
\hline \multicolumn{8}{|l|}{ Female } \\
\hline \multirow[t]{7}{*}{ No diabetes } & $30-39$ & $25(13-50)$ & 344 & $3.7(0.5-26.3)$ & 293 & $2.6(0.3-18.6)$ & 252 \\
\hline & $40-49$ & $28(21-38)$ & 1593 & $6.4(3.2-12.9)$ & 1341 & $4.7(2.3-9.3)$ & 1130 \\
\hline & $50-59$ & $51(44-59)$ & 3754 & $8.4(5.6-12.6)$ & 3117 & $6.2(4.2-9.3)$ & 2620 \\
\hline & $60-69$ & $88(81-96)$ & 7131 & $14(11-17)$ & 5690 & $16(14-20)$ & 4795 \\
\hline & $70-79$ & $216(207-225)$ & 13298 & $38(34-42)$ & 9457 & $34(31-38)$ & 7747 \\
\hline & 80-89 & $403(391-415)$ & 16908 & $78(72-84)$ & 10160 & $73(69-79)$ & 8074 \\
\hline & $90+$ & $629.9(604-656)$ & 5682 & $140(120-150)$ & 2853 & $130(110-140)$ & 2179 \\
\hline \multirow[t]{7}{*}{ Diabetes } & $30-39$ & $88(37-212)$ & 61 & $0(0-0)$ & 53 & $45(15-140)$ & 46 \\
\hline & $40-49$ & $73(47-115)$ & 290 & $28(13-62)$ & 235 & $17(7.2-41)$ & 193 \\
\hline & $50-59$ & $94(74-119)$ & 830 & $31(20-49)$ & 668 & $26(17-39)$ & 559 \\
\hline & $60-69$ & 172 (153-193) & 2081 & $30(22-40)$ & 1532 & $32(25-41)$ & 1270 \\
\hline & $70-79$ & 277 (259-296) & 4093 & $58(49-68)$ & 2749 & $60(52-69)$ & 2201 \\
\hline & $80-89$ & 419 (396-444) & 3848 & $100(91-120)$ & 2240 & $110(93-120)$ & 1714 \\
\hline & $90+$ & $665(600-738)$ & 848 & $190(150-240)$ & 414 & $180(140-220)$ & 288 \\
\hline
\end{tabular}

determinant of both death and myocardial infarction as the absolute risk of these outcomes almost doubles with each age decade (Table 1 and 2).

Although female gender carries a risk of 1.6 that of males in unadjusted analysis, after correction for age, this factor is no longer significant (Table 3).

\section{Discussion}

This study presents population based figures for risks of recurrence of MI or death for 30,407 people with diabetes following an MI compared with those without diabetes. These tables can give the absolute risks and the relative risks of MI and/or death stratified by age and sex. Findings suggest that diabetes is an important risk factor for younger patients and is associated with poorer outcome especially for re-infarction. This is supported by the finding that many young people experiencing MI have undiagnosed diabetes but an absence of other risk factors [17]. Risk factors specifically associated with diabetes include diabetes increased atherosclerotic plaque formation and thrombosis [18] associated with hypergycemia [19].

The control population risk is constant with time (e.g. 0.46 per 1,000 in the age $30-39$ over $0-90$ days and 0.71 over $181-365$ days $(0.36$ per 1,000 if this is taken as a 90 day period- Table 4). There are no existing studies showing survival to re-MI in a population based study [11]. Thus, this study provides survival tables that can be used to improve information regarding prognosis for patients, to inform treatment strategies for people having an AMI and to inform driver licensing and insurance guidelines. This is a population based study based on 30,407 people with diabetes. No other study has looked at a total population cohort to give rates of recurrence of infarction stratified by age and sex. This data is not possible to generate using meta-analysis of existing cohort studies [20] and can only be developed using routinely collected data.

Data on mortality are comparable to that previously published showing a 2 fold increase in mortality in the 


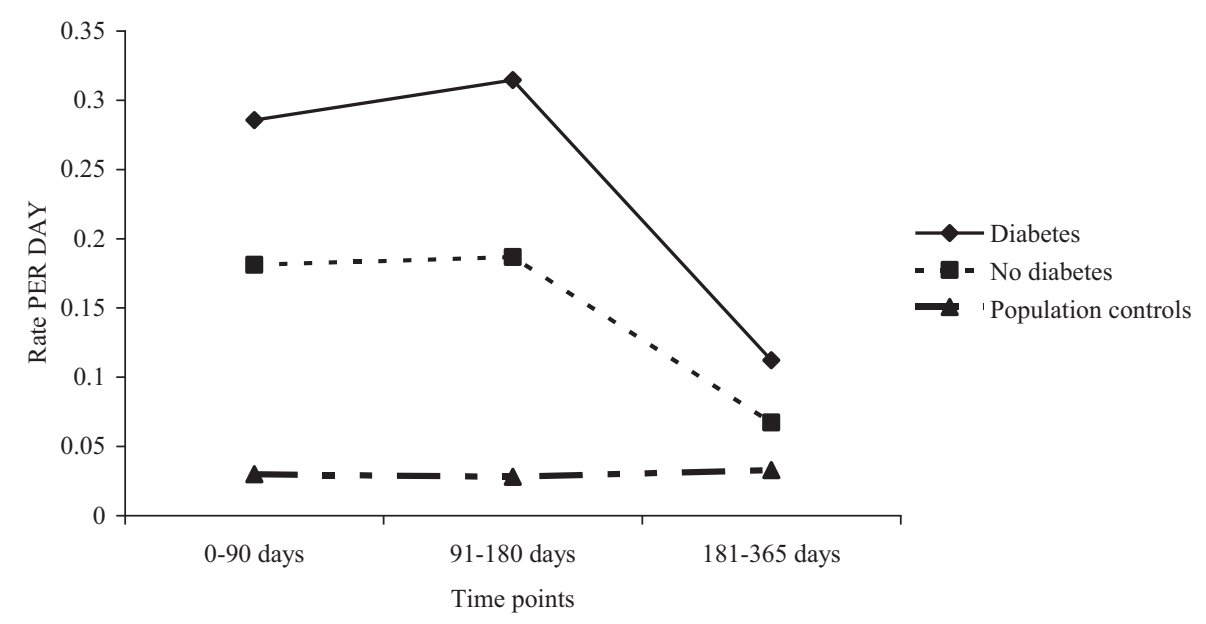

Rate of death among men aged 70-79

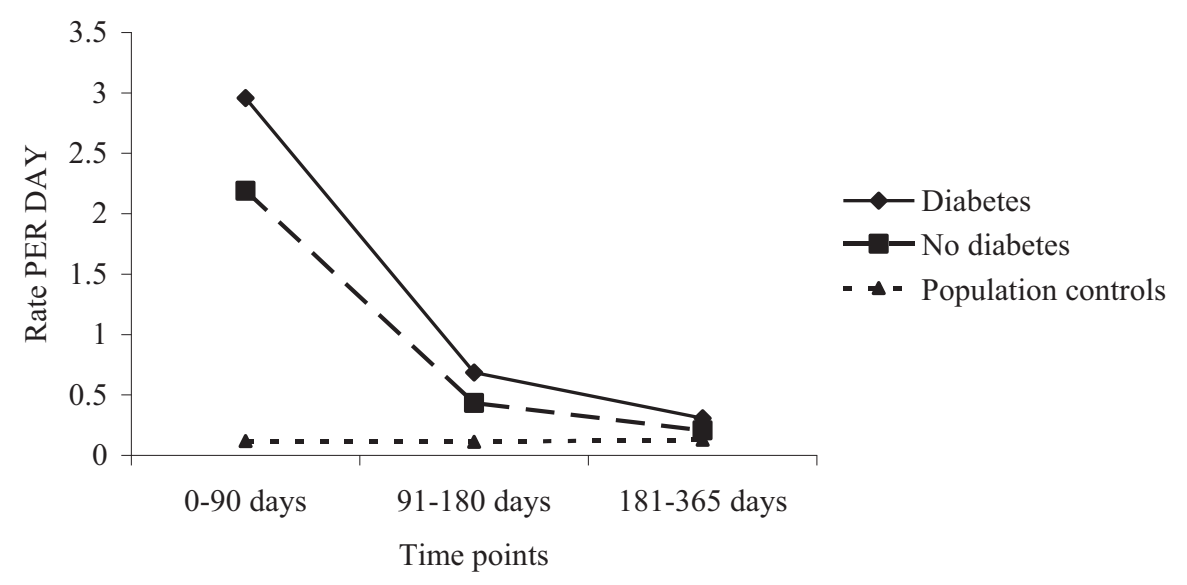

Figure 1 Rate of MI or death with time. (Males aged 70-79).

short term $[9,10]$ and $40 \%$ increase in the longer term $[2,13]$ for MI patients with and without diabetes.

However, using routine data does have its limitations. Coding and recording of all AMI's in the hospital admissions dataset is not perfect and there may be an underestimate of number of AMI's by approximately $10 \%$, as some MI's are recorded using imprecise coding. In addition, approximately $10 \%$ of the 'non-diabetes' group may have had diabetes but the code was missing from the hospital admission data.

Calculating unbiased population risks is difficult due to absence of disease registers with $100 \%$ coverage and selection bias[20] and restricted inclusion criteria may lead to distorted risks. Therefore, routinely collected data, although imperfect, is currently the closest we have to a population based disease register which supports low cost analysis of up to date and current rates of disease and survival times for hospitalised MI. However, to fully understand the explanatory or confounding factors and to incorporate them into a multivariate cox regression analysis, linkage is needed with more data sources. For example factors which need to be incorporated would include; other co-morbidities (peripheral arterial disease, chronic pulmonary disease, hypertension, hyperlipidemia, chronic kidney disease and others), lifestyle factors (smoking, diet, physical activity, physiotherapy), treatments prescribed (beta blockers, streptokinase, aspirin, statins (pre and post 
Table 2 Mortality and re-infarction rate following a AMI per 1,000 people

\begin{tabular}{|c|c|c|c|c|c|c|c|}
\hline Gender and Co-morbidity & Age & $\begin{array}{l}\text { 0-90 days: } \\
\text { rate }(95 \% \mathrm{Cl})\end{array}$ & $\mathrm{n}$ & $\begin{array}{l}\text { 91-180 days: } \\
\text { rate }(95 \% \mathrm{Cl})\end{array}$ & $\mathrm{n}$ & $\begin{array}{l}\text { 181-365 days: } \\
\text { rate }(95 \% \mathrm{Cl})\end{array}$ & $\mathrm{n}$ \\
\hline \multicolumn{8}{|l|}{ Male } \\
\hline \multirow[t]{7}{*}{ No diabetes } & $30-39$ & $20(14-28)$ & 1635 & $9.1(5.2-16)$ & 1414 & $4.8(2.5-9.2)$ & 1226 \\
\hline & $40-49$ & $24(20-28)$ & 7894 & $9.5(7.3-12.2)$ & 6784 & $8.9(7.1-11.1)$ & 5722 \\
\hline & $50-59$ & $43(40-46)$ & 15712 & $11(9.5-13)$ & 13276 & $8.6(7.3-10.1)$ & 11306 \\
\hline & $60-69$ & $88(84-93)$ & 18701 & $24(21-27)$ & 15204 & $20(18-22)$ & 12761 \\
\hline & $70-79$ & $213(206-221)$ & 19714 & $56(52-60)$ & 14224 & $49(46-52)$ & 11770 \\
\hline & $80-89$ & $421(409-434)$ & 14732 & $113(106-121)$ & 8904 & $110(100-120)$ & 6989 \\
\hline & $90+$ & 735 (693-779) & 2548 & $202(176-232)$ & 1192 & $190(170-220)$ & 870 \\
\hline \multirow[t]{7}{*}{ Diabetes } & $30-39$ & $19(6-59)$ & 170 & $29(11-78)$ & 150 & $5.34(0.75-38)$ & 123 \\
\hline & $40-49$ & $53(40-70)$ & 987 & $12(6-23)$ & 811 & $24(16-36)$ & 701 \\
\hline & $50-59$ & $87(76-100)$ & 2626 & $28(21-36)$ & 2120 & $22(17-29)$ & 1808 \\
\hline & $60-69$ & $154(142-167)$ & 4496 & 47 (40-55) & 3433 & $46(40-53)$ & 2875 \\
\hline & $70-79$ & $292(277-307)$ & 6133 & $90(81-100)$ & 4175 & $75(68-84)$ & 3374 \\
\hline & $80-89$ & $453(427-480)$ & 3528 & 174 (156-195) & 2074 & $150(140-170)$ & 1529 \\
\hline & $90+$ & 701 (634-776) & 402 & 301 (226-402) & 190 & 190 (130-270) & 124 \\
\hline \multicolumn{8}{|l|}{ Female } \\
\hline \multirow[t]{7}{*}{ No diabetes } & $30-39$ & $25(13-50)$ & 344 & $11(3.6-35)$ & 293 & $5.2(1.3-21)$ & 252 \\
\hline & $40-49$ & $38(29-49)$ & 1593 & $14(8.6-22)$ & 1341 & $9.9(6.1-16)$ & 1130 \\
\hline & $50-59$ & $60(51-68)$ & 3754 & $13(12-21)$ & 3117 & $12(9-16)$ & 2620 \\
\hline & $60-69$ & 100 (93-108) & 7131 & $25(21-29)$ & 5690 & $21(18-25)$ & 4795 \\
\hline & $70-79$ & $232(223-241)$ & 13298 & $54(49-59)$ & 9457 & $46(42-50)$ & 7747 \\
\hline & 80-89 & $424(412-435)$ & 16908 & $103(97-110)$ & 10160 & 93 (87-98) & 8074 \\
\hline & $90+$ & $646(620-673)$ & 5682 & 165 (150-182) & 2853 & $140(130-160)$ & 2179 \\
\hline \multirow[t]{7}{*}{ Diabetes } & $30-39$ & $88(37-212)$ & 61 & $21(2.9-148)$ & 53 & $60(23-160)$ & 46 \\
\hline & $40-49$ & $100(68-147)$ & 290 & $51(28-93)$ & 235 & $38(21-69)$ & 193 \\
\hline & $50-59$ & $99(79-125)$ & 830 & 47 (33-68) & 668 & $34(24-48)$ & 559 \\
\hline & $60-69$ & $188(168-210)$ & 2081 & $60(48-74)$ & 1532 & $49(40-60)$ & 1270 \\
\hline & $70-79$ & 301 (283-321) & 4093 & $97(86-110)$ & 2749 & $81(72-92)$ & 2201 \\
\hline & $80-89$ & 459 (433-484) & 3848 & $144(128-162)$ & 2240 & $130(120-150)$ & 1714 \\
\hline & $90+$ & 701 (634-776) & 848 & 227 (182-283) & 414 & $200(160-250)$ & 288 \\
\hline
\end{tabular}

Table 3 Cox regression analysis for risk of re-MI or death

\begin{tabular}{llll}
\hline Time from initial AMI & Risk factor & Crude Hazard Ratio $\mathbf{9 5 \% C l )}$ & Adjusted Hazard Ratio $\mathbf{9 5 \% C l )}$ \\
\hline 0-90 days & Diabetes & $1.3(1.26-1.33)$ & $1.16(1.12-1.19)$ \\
& Heart failure & $2.6(2.5-2.6)$ & $1.6(1.6-1.69)$ \\
& Age group (per increase in decade) & $1.06(1.06-1.06)$ & $1.04(1.04-1.05)$ \\
& Heart surgery for current Ml & $0.16(0.15-0.17)$ & $0.28(0.27-0.3)$ \\
& Female gender & $1.6(1.56-1.63)$ & $1.0(0.98-1.03)$ \\
91-180 days & Diabetes & $1.71(1.6-1.8)$ & $1.5(1.4-1.6)$ \\
& Heart failure & $3.1(2.96-3.2)$ & $1.96(1.86-2.1)$ \\
& Age group (per increase in decade) & $1.06(1.06-1.07)$ & $1.05(1.04-1.05)$ \\
& Heart surgery for current Ml & $0.24(0.21-0.26)$ & $0.42(0.37-0.46)$ \\
$180-365$ days & Female gender & $1.52(1.4-1.6)$ & $0.94(0.9-1.0)$ \\
& Diabetes & $1.66(1.57-1.75)$ & $1.5(1.4-1.5)$ \\
& Heart failure & $3.06(2.9-3.2)$ & $1.93(1.8-2.03)$ \\
& Age group (per increase in decade) & $1.066(1.063-1.068)$ & $1.055(1.05-1.06)$ \\
& Heart surgery for current Ml & $0.299(0.27-0.32)$ & $0.52(0.47-0.57)$ \\
& Female gender & $1.5(1.4-1.6)$ & $0.94(0.9-0.99)$ \\
\hline
\end{tabular}


Table 4 Rate of morality or infarction in controls (with no previous history of AMI) per 1,000 people

\begin{tabular}{llllllll}
\hline Gender & Age & $\mathbf{0 - 9 0}$ days: rate & $\mathbf{n}$ & $\mathbf{9 1 - 1 8 0}$ days: rate & $\mathbf{n}$ & $\mathbf{1 8 1 - 3 6 5}$ days: rate & $\mathbf{n}$ \\
\hline Male & & & & & & & \\
& $30-39$ & 0.46 & 226,251 & 0.38 & 225,283 & 0.71 & 224,530 \\
& $40-49$ & 0.85 & 210,842 & 0.78 & 210,255 & 1.8 & 209,697 \\
& $50-59$ & 2.3 & 202,353 & 2.16 & 201,602 & 4.7 & 14,923 \\
& $60-69$ & 4.9 & 149,269 & 5.06 & 148,381 & 11.7 & 100,052 \\
& $70-79$ & 13.3 & 102,893 & 12.45 & 101,414 & 29.07 & 37,922 \\
& $80-89$ & 30.0 & 40,259 & 26.99 & 39,019 & 68.78 & 4,487 \\
Female & $90+$ & 58.7 & 5,061 & 52.64 & 4,758 & 125.55 & 217,754 \\
& $30-39$ & 0.17 & 219,185 & 0.17 & 218,507 & 0.3942 & 202,860 \\
& $40-49$ & 0.46 & 203,768 & 0.57 & 203,322 & 1.05 & 198,432 \\
& $50-59$ & 1.40 & 199,492 & 1.13 & 198,944 & 2.39 & 152,294 \\
& $60-69$ & 3.02 & 153,572 & 2.93 & 152,927 & 6.88 & 124,827 \\
& $70-79$ & 8.42 & 127,186 & 8.22 & 125,988 & 19.44 & 72,464 \\
\end{tabular}

Table 5 Relative risk of death or MI post hospitalization for MI

\begin{tabular}{|c|c|c|c|c|c|c|c|c|c|}
\hline & & $\begin{array}{l}0-90 \text { days } \\
(95 \% \mathrm{Cl})\end{array}$ & $\begin{array}{l}91-180 \text { days } \\
(95 \% \mathrm{Cl})\end{array}$ & $\begin{array}{l}181-365 \text { days } \\
(95 \% \mathrm{Cl})\end{array}$ & & & $\begin{array}{l}0-90 \text { days } \\
(95 \% \mathrm{Cl})\end{array}$ & $\begin{array}{l}91-180 \text { days } \\
(95 \% \mathrm{Cl})\end{array}$ & $\begin{array}{l}181-365 \text { days } \\
(95 \% \mathrm{Cl})\end{array}$ \\
\hline Male & & & & & Female & & & & \\
\hline No & $30-39$ & $43.1(29.1-63.7)$ & $23.9(13.3-42.9)$ & $6.76(3.0-15.3)$ & No & $30-39$ & $148.6(71.5-308.5)$ & $64.3(20.7-200)$ & $13.1(2.3-73.6)$ \\
\hline \multirow[t]{6}{*}{ diabetes } & $40-49$ & $28.3(23.1-34.7)$ & $12.2(9.1-16.2)$ & $4.9(3.7-6.6)$ & diabetes & $40-49$ & $82.3(59.8-113.3)$ & $24.2(14.9-39.4)$ & $9.4(5.2-17.1)$ \\
\hline & $50-59$ & $18.6(16.5-20.9)$ & $5.2(4.3-6.2)$ & $1.8(1.5-2.2)$ & & $50-59$ & $42.8(36.1-50.9)$ & $14.0(10.2-19)$ & $5.0(3.5-7.2)$ \\
\hline & $60-69$ & $18.0(16.5-19.6)$ & $4.7(4.2-5.3)$ & $1.6(1.5-1.9)$ & & $60-69$ & $33.1(29.6-37.2)$ & $8.3(6.9-10.1)$ & $3.1(2.5-3.8)$ \\
\hline & $70-79$ & $16.1(15.1-17.0)$ & $4.5(4.1-4.9)$ & $1.7(1.5-1.8)$ & & $70-79$ & $27.5(25.7-29.4)$ & $6.5(5.9-7.2)$ & $2.3(2.1-2.6)$ \\
\hline & $80-89$ & $14.1(13.2-14.9)$ & $4.2(3.8-4.6)$ & $1.6(1.5-1.7)$ & & 80-89 & $19.3(18.3-20.3)$ & $4.8(4.4-5.2)$ & $1.7(1.6-1.9)$ \\
\hline & $90+$ & $12.5(11.2-19.6)$ & $3.8(3.2-4.5)$ & $1.5(1.3-1.8)$ & & $90+$ & $11.8(11-12.6)$ & $3.2(2.9-3.7)$ & $1.1(0.97-1.2)$ \\
\hline \multirow[t]{7}{*}{ Diabetes } & $30-39$ & $41.0(13.6-123.3)$ & 75.4 (29-196.2) & $7.5(0.6-84)$ & Diabetes & $30-39$ & $518(217-1235)$ & $122(18.7-798.8)$ & $152(47.6-487.3)$ \\
\hline & $40-49$ & $62.1(45.9-84.0)$ & $15.2(7.9-29)$ & $13.5(8.3-21.8)$ & & $40-49$ & $218(146-325)$ & 90.7 (50.9-161.6) & $35.9(17.4-74.1)$ \\
\hline & $50-59$ & $38.0(32.6-44.2)$ & $12.8(9.8-16.7)$ & $4.7(3.5-6.5)$ & & $50-59$ & $71(56-90)$ & $41.9(29.0-60.3)$ & $14.3(9.1-22.3)$ \\
\hline & $60-69$ & $31.4(28.4-34.7)$ & $9.2(7.7-10.8)$ & $3.9(3.3-4.7)$ & & $60-69$ & $62.2(54.8-70.7)$ & $21.03(17.0-26.1)$ & $7.1(5.5-9.1)$ \\
\hline & $70-79$ & $21.9(20.6-23.4)$ & $7.2(6.4-8.1)$ & $2.5(2.3-2.9)$ & & $70-79$ & $35.8(33.2-38.6)$ & $11.8(10.4-13.5)$ & $4.2(3.6-4.8)$ \\
\hline & 80-89 & $15.1(14.1-16.1)$ & $6.4(5.8-7.2)$ & $2.1(1.9-2.5)$ & & 80-89 & $20.9(19.7-22.1)$ & $6.74(6.0-7.5)$ & $2.5(2.2-2.8)$ \\
\hline & $90+$ & $11.9(10.5-13.6)$ & $5.7(4.5-7.3)$ & $1.5(1.0-2.2)$ & & $90+$ & $12.8(11.8-13.8)$ & $4.5(3.7-5.4)$ & $1.5(1.2-2.0)$ \\
\hline
\end{tabular}

$\mathrm{MI})$ ), location of infarction (anterior, inferior) and type of AMI (STEMI, non-STEMI). To improve survival models linkage will be needed with primary care datasets where the most complete source of morbidity data is held.

\section{Conclusions}

In summary, this study provides population based age stratified absolute risks of re-infarction or death for people with diabetes. These tables are based on all hospital admissions in England and Wales for the period 20032006 and these absolute risks can be used as reference tables in clinical care, industry and in informing driving legislation.

\section{List of abbreviations}

AMI: acute myocardial infarction; AR: Administrative Register; FEC: finished consultant episode; OPCS: Office of Population, Censuses and Surveys: Classification of Surgical Operations and Procedures; ONS: Office for National Statistics; HES: Hospital Episode Statistics for England; ICD: International Classification of Disease; MINAP: Myocardial Ischaemia National Audit Project; NHS: National Health Service; NSF: National Service Framework for Coronary Heart Disease; PEDW: Patient Episode Database for Wales; RR: relative risk; STEMI: ST segment elevation myocardial infarction.

\section{Acknowledgements}

This study was funded by the Department for Transport, UK.

Author details

${ }^{1}$ School of Medicine, Swansea University, SA2 8PP, UK. ${ }^{2}$ Health Solutions Wales. Brunel House, Cardiff, CF24 OHA, UK. 


\section{Authors' contributions}

The study was designed by SB, RL, CW, and RW. Data extraction was conducted by $S M$ and $G M$. Analysis was undertaken by $S B, R C, M G$ and RL. The first draft of the manuscript was undertaken by SB, RC and SM and comments and changes were made by MG, CW, GJ, RW and RL. All authors have approved the final manuscript.

\section{Competing interests}

The authors declare that they have no competing interests.

Received: 8 February 2010 Accepted: 14 June 2010

Published: 14 June 2010

\section{References}

1. Stone PH, Muller JE, Hartwell T, York BJ, Rutherford JD, Parker CB, Turi ZG, Strauss HW, Willerson JT, Robertson T, et al: The effect of diabetes mellitus on prognosis and serial left ventricular function after acute myocardial infarction: contribution of both coronary disease and diastolic left ventricular dysfunction to the adverse prognosis. The MILIS Study Group. J Am Coll Cardiol 1989, 14(1):49-57.

2. Donnan PT, Boyle DI, Broomhall J, Hunter K, MacDonald TM, Newton RW, Morris AD: Prognosis following first acute myocardial infarction in Type 2 diabetes: a comparative population study. Diabet Med 2002, 19(6):448-55.

3. Smith JW, Marcus Fl, Serokman R: Prognosis of patients with diabetes mellitus after acute myocardial infarction. Am J Cardiol 1984, 54(7):718-21.

4. Molstad P, Nustad M: Acute myocardial infarction in diabetic patients. Acta Med Scand 1987, 222(5):433-7.

5. American Diabetes Association: Consensus statement: role of cardiovascular risk factors in prevention and treatment of macrovascular disease in diabetes. Diabetes Care 1993, 16(Supp 2):72-8.

6. Acharjee S, Qin J, Murphy SA, McCabe C, Cannon CP: Distribution of traditional and novel risk factors and their relation to subsequent cardiovascular events in patients with acute coronary syndromes (from the PROVE IT-TIMI 22 trial). Am J Cardiol 105(5):619-23.

7. Cantrill JA, D'Emanuele A, Dornan TL, Garcia S: A survey of drug treatment and outcomes in diabetic patients with acute myocardial infarcts. J Clin Pharm Ther 1995, 20(4):207-13.

8. Nichols GA, Hillier TA, Erbey JR, Brown JB: Congestive heart failure in type 2 diabetes: prevalence, incidence, and risk factors. Diabetes Care 2001, 24(9):1614-9.

9. Wannamethee G, Whincup PH, Shaper AG, Walker M, MacFarlane PW: Factors determining case fatality in myocardial infarction "who dies in a heart attack"? Br Heart J 1995, 74(3):324-31.

10. Yudkin JS, Oswald GA: Determinants of hospital admission and case fatality in diabetic patients with myocardial infarction. Diabetes Care 1988, 11(4):351-8.

11. Ulvenstam G, Aberg A, Bergstrand R, Johansson S, Pennert K, Vedin A, Wilhelmsen L, Wilhelmsson C: Long-term prognosis after myocardial infarction in men with diabetes. Diabetes 1985, 34(8):787-92.

12. Mulnier HE, Seaman HE, Raleigh VS, Soedamah-Muthu SS, Colhoun HM, Lawrenson RA, de Vries CS: Risk of myocardial infarction in men and women with type 2 diabetes in the UK: a cohort study using the General Practice Research Database. Diabetologia 2008, 51(9):1639-45.

13. Ouhoummane N, Abdous B, Emond V, Poirier P: Impact of diabetes and gender on survival after acute myocardial infarction in the Province of Quebec, Canada-a population-based study. Diabet Med 2009, 26(6):609-16.

14. Lyons RWR, Gravenor M, Brophy S, Weston C, Macey S, Cooksey R, John G Road Safety Research Report 107 Analysis of Risk Outcomes for Cardiac Conditions. 2009 [http://www.dft.gov.uk/pgr/roadsafety/research/rsrr/ theme6/report107/], Accessed April 2010.

15. [http://www.rcplondon.ac.uk/CLINICAL-STANDARDS/ORGANISATION/ PARTNERSHIP/Pages/MINAP-.aspx], accessed: April 2010.

16. ONS statistics. 2008 [http://www.statistics.gov.uk/pdfdir/miga1109.pdf], accessed: April 2010.

17. Lee GK, Lee LC, Liu CW, Lim SL, Shi LM, Ong HY, Lim YT, Yeo TC: Framingham risk score inadequately predicts cardiac risk in young patients presenting with a first myocardial infarction. Ann Acad Med Singapore 39(3):163-7.
18. Jacoby RM, Nesto RW: Acute myocardial infarction in the diabetic patient: pathophysiology, clinical course and prognosis. J Am Coll Cardiol 1992, 20(3):736-44.

19. Cruz-Gonzalez I, Chia S, Raffel OC, Sanchez-Ledesma M, Senatore F, Wackers FJ, Nathan DM, Jang IK: Hyperglycemia on admission predicts larger infarct size in patients undergoing percutaneous coronary intervention for acute ST-segment elevation myocardial infarction. Diabetes Res Clin Pract 88(1):97-102.

20. Brophy S, Mannan S, John A, Cheung W-I, Lyons R, Weston CRW: Road Safety Research Report No 65. Risk of futher acute vascular events following an initial myocardial infarction or stroke. 2006 [http://www.dft. gov.uk/pgr/roadsafety/research/rsrr/theme6/riskofacutevasculareventsfol.pdf], accessed April 2010.

\section{Pre-publication history}

The pre-publication history for this paper can be accessed here: http://www.biomedcentral.com/1471-2458/10/338/prepub

\section{doi:10.1186/1471-2458-10-338}

Cite this article as: Brophy et al:: Population based absolute and relative survival to 1 year of people with diabetes following a myocardial infarction: A cohort study using hospital admissions data. BMC Public Health 2010 10:338.

\section{Submit your next manuscript to BioMed Central and take full advantage of:}

- Convenient online submission

- Thorough peer review

- No space constraints or color figure charges

- Immediate publication on acceptance

- Inclusion in PubMed, CAS, Scopus and Google Scholar

- Research which is freely available for redistribution

Submit your manuscript at www.biomedcentral.com/submit
Ciomed Central 